\title{
Study on the effective teaching methods to promote volleyball technology
}

\author{
Zhao Feng \\ Xijing University, Xi'an, 710123, China
}

Keywords: volleyball, sports skill, teaching quality

\begin{abstract}
In the sports teaching, effective goal setting can improve the teaching quality. In this article, we use the methods of experimental contrast, questionnaire and the data analysis to research the effect to improve the teaching level and students' interest in autonomous learning of the target teaching and to promote the improvement of the students' technical level so as to lay the foundation for students' lifelong sports. The "goal setting" teaching method can target to the students. It can guide students to learn for the established goals and can improve the students' sports level effectively and to promote the development of students' ability.
\end{abstract}

\section{Introduction}

The pursuit of health is an indispensable part in people's life. Health is the basic of working, studying and all of other things. We will have nothing without health. Students are the hope of the motherland, shouldering the future of the nation. But under the background of China exam oriented education, the students' health is worrying, especially for middle school students. Due to the pressure of the entrance examination, the extracurricular activities time is greatly reduced. This requires teachers to help students completing the teaching contents with high quality and high efficiency in the limited physical education curriculum. So to achieve the goal of sports fitness and train the students' "lifetime sports" consciousness of active participation in sports activities.

As the students of sports education professional, after years of learning and observation, we found that some students will appear adaptive response when they face the failure in sports activities. They will search for the reason of their failure actively, seek solutions and strategies and maintain the interest in sports activities, willing to accept new challenges. But others are just the opposite. They became very depressed, no longer willing to participate in sports activities. Why did appear the different tendencies when they faced with the same failure? The goal orientation theory points out that the reason is the students held the different goal orientations in sports activities. We can guide the students to form proper goal orientation by effective methods. So, in sports learning and training, how to guide the students to form proper goal orientation and set the appropriate and effective teaching objectives requires physical education teachers to play their active role. We can make students grasp the sports skill better and improve the effect of exercise by stimulating students' physical education learning potential, guide and promote the students' physical education learning activities.

\section{The application of goal setting in teaching process}

Goal setting refers to the planning of the result that the motivated activities will achieve at last. The correct and effective goals can be the energy to stimulate, guide and organize the activities. It is an important driving behavior and guiding force. The goal setting theory is putted forward in 1968 by Ediwin A Locke who is the professor of management science and psychology in University of Maryland. The theory of goal setting is mainly based on this assumption : conscious goals influence behavior (Yang Xiujun, 2004). In this theory, the goal has incentive effect itself, can target the needs of the people into motivation, make people's bank to work toward a direction and compare the results of their behavior with the established goals then to adjust and amend in time, so to achieve the goal.

In the sports activities, the goal setting means to determine a physical study and physical 
exercise goal that in a certain time can achieve and determine the steps, strategy and the schedule to reach the goal.

\section{Analysis on the advantage of the application of goal setting teaching method}

Goal setting is directly related to the direction and intensity of the motivation. Effective goal can concentrate the power of people. It is an important driving force of behavior. In the sports teaching, the goal setting teaching method plays an important role in improving the level of technical action subject and the quality of contact and strengthening the confidence.

\section{Goal setting can help students focus their attention on the task}

Effective goal setting can indicate the direction for students' learning. When students have no specific teaching objectives, their attention will be relatively easy to disperse and they will be confused about the learning task. However, to set a specific goal of teaching can help students focus on this tasks related goal, encourage students to work hard to achieve their goals.

\section{Goal setting is conducive to the students' subjectivity under the guidance of teachers}

"Target teaching" can mobilize enthusiasm and initiative of the teacher which is dominated and student which is the main body. Between teachers and students, form an interactive process of exchanges and cooperation and common development. The teaching goal is both for teachers and students. In order to achieve the teaching general objective, the teachers carefully research the unit structure and try to put the unit target system in to the design of each class organically. Because the students understand the incentive effect of the target, so they have to meet the needs of the target. And associated with every implementation of specific goal, students produce more feeling of success and joy. Successful experience will encourage individual initiative to learn and create, arouse the students' interest in learning volleyball, fully play the principle status of students.

\section{Goal setting is beneficial to cultivate the students' good personality}

The evaluation of goal setting is mainly based on the improving degree of student. Emphasis on individual effort rather than ability, Make students compare with their own, rather than with others. Let the students to see their progress, play down the gap with others. Students under the guidance of unit goals, strive to achieve the teaching goal. This changed the passive learning phenomenon which called "do not have enough to eat" and "finish" that is widespread in the conventional teaching. Stimulating the students' learning desire and passion, and fully mobilizing students' self-consciousness and initiative is conducive to the cultivation of the students' good personality and development.

Goal Setting Is Helpful To Cultivate Students' Self-Learning Ability And Form The Concept Of Lifelong Sports

In the goal setting teaching, teachers guide students to think and explore the methods of learning actively, leave most of the time in the classroom for students to practice, consolidate the technical movements and expand the discussion of learning methods. They can see the superiority and insufficiency from the self assessment and peer assessment. Therefore, goal setting teaching focus on training the students' learning methods and learning ability. Students have self-learning ability and good learning methods, learning will become a happy thing and a life-long learning concept will be formed.

\section{Goal setting teaching experiment in volleyball mat ball technology}

The control group and the experimental group were subjected to the basic level test (pre-test), and the pre experimental arrangement was carried out before the teaching experiment.

1) pretest indicators

Including the pretest index: standing long jump (m), measurement tools for measuring tape; three meters (seconds), mobile measurement tool is the stopwatch, height (m), measurement tool is the tape.

2) at the end of the experiment, take the volleyball skill level test (post test) and questionnaire survey 


\section{3) post test index}

The post test index include: volleyball technical assessment, performance standards, and at the end of the volleyball technical level test everyone do the questionnaire then do the statistical analysis of data and information.

Teaching experiment process and method

The control group was given routine teaching method.

The conventional teaching process: announce the contents and requirements -- preparation activities -- teachers, teachers guide students to practice -- correct errors and guide students -- the final exam (summative evaluation).

The experimental group adopted the target teaching method.

The process of goal teaching experimental: develop an overall target for volleyball class -analysis the teaching contents and decompose the teaching content into several small units and clear ability requirements related units -- according to the requirements to develop specific points -according to students' basic ability level determine the target levels-- exercise on same level -- form assessment-- practice in groups, summary - final exam summative evaluation.

The principles that should be followed in the teaching of goal setting.

1)set up a combination of long-term and short-term goal.

The long-term goal is hard to persevere, but if the long-term goals putted into short-term goals, you can maintain high motivation and morale for a long period, because each realization of a small sub goal can make people relatively quickly, clearly see their progress, see the causality between their own efforts and progress, get the desire and motivation of overcoming the difficulties in order to achieve a sub goal, the more goals the athlete will achieve, the more success feeling they will experience and the stronger the confidence is also. Therefore, it is very important to put the long-term goals into reality, specific medium-term goals and short-term in physical education learning and training .

In general, the short-term goal is more effective than the long-term goal, to human action it is most likely to have an immediate boost, but there must be a long-term goal to guide to let the behavior more consciously and unremittingly. Therefore, when setting the target for the students, we should combine the long-term goals with short-term goals and put long-term goals into short-term goals. When the short-term goals are completed, the possibility of completing long-term goals will naturally increase.

For example, in the volleyball teaching process, the success rate of a student in digging to fixed-point was $40 \%$, the PE teacher put forward that the student should achieve the ultimate goal of $80 \%$ shooting in the final. At the beginning, the student think that the target is difficult to achieve, have quit at this time. Then the teacher should help students put the ultimate goal into stages, classification goals and the lowest target according to the current personal ability of the student. The current level of the students is $40 \%$ hit rate, then a sub goal is to improve the hit rate of to $50 \%$, next sub goal is to improve the hit rate to $60 \%$, sub goal three may in order to improve the hit rate of to $70 \%$, the fourth sub goal is to improve the hit rate to $40 \%$, so as to achieve the ultimate goal of $80 \%$. In the process of achieving the goals, if the physical education teachers find that the students have difficulty to reach a goal, two aspects should be analyzed. One possibility is that the ladder between two sub target may be set too high, beyond the existing ability level of students. This time the "step goal" can be put into two or more steps, another possibility is that students do not get proper guidance, they do not know how to do next step or get the skill to overcome the obstacles to the next ladder. PE Teachers should help students to master this skill.

2) set specific, clear goals

Clear, specific, quantitative analysis conducted targets have a good effect to inspire the motivation. The fuzzy, quantitative analysis can not be conducted goals have no effect inspire the motivation.

Many experiments show that set specific, measurable goals can produce more motive function and lead to better results than just set the general goal of than just setting general goals. For example, "on the wall pad three groups, 30 in each group, five minutes group" is more effective 
than "on the wall pad, pad to the more the better". The explicit goal can not only lead to a clear and efficient behavior, but also help to evaluate the results, help to quantitatively examine whether reached the goal and the feedback is important for the target motivation. For a sports teacher, the goal that "I will strive to improve the students' PE Achievement "is not so accurate as the goal that "my goal is to improve the students' sports compliance rate increased from $70 \%$ to $90 \%$ ", so the conductions for PE teachers is smaller.

3) to set both challenging and feasible goals according to the practical ability of students

Sports teachers and students can correctly judge the ability of students is an important basis in setting goals. If They can not correctly analyze and evaluate the practical ability of the students, they may make the goal too high or too low, which is not practical.

A good goal should not only have a certain degree of difficulty, but also can be achieved . It is best that the students need to go through great efforts to achieve the level. Only in this way the goal can be full of challenging and can stimulate students' motivation. If the target is too easy to complete, the students will experience no challenging. It is unable to stimulate exercise and learning motivation. On the contrary, it's too difficult, students repeated efforts still cannot reach this goal, it will make students produce frustration and doubt their own ability, and even give up efforts. This requires physical education teachers should not only grasp the students' body development patterns and movement characteristics of individual projects, but also know more about each student's practical ability and the students' ability to self assessment in setting goals for the students. Therefore, in order to ensure that the target is difficult and possible, the ability level of the students recently can be as a reference, and if necessary correction targets to adapt to the changing of the situation.

4) the task achieved goal should be set, rather than the end result

Task goal emphasize to do the longitudinal self comparison, pay attention to personal effort, master the skills and finish the task, it helps to maintain and improve the internal motivation. Therefore, as long as their own efforts and refresh their personal records, they will have a sense of success. Results target stressed their horizontal compared with others, pay attention to social reference, aiming at more than others, the results target damage against the internal motivation. For example, Classmate a efforts less than classmate b, but the scores of a and b are equal, a can also produce a feeling of success. In the practical physical education teaching, teachers should try to build an atmosphere of high task orientation, is conducive to the cultivation of the students' good personality and development.

5) to set goals and provide feedback

To provide feedback of goals can help students understand the situation of activities on the road to the goal, and make timely adjustments and improvements, such as a study.Four groups of students were trained in different conditions and produced different results. The first group only set goals without feedback information, the second group only gave the feedback of the activities, the target was not set, the third group has set the target and obtain the feedback information, the fourth groups has neither the goal nor the feedback information. Research results show that the third group that both set up a goal and won the feedback effect of is the best ( Table 1). Therefore, in the sports teaching, the teacher should not only set effective goals for the students, and provide timely feedback. In addition, periodic feedback should be positive for students, and points out the direction of its future efforts to improve and improvement.

Table.1 Comparison of teaching process between the experimental group and the control group

\begin{tabular}{|l|l|}
\hline Experimental group (target teaching) & control group (traditional teaching) \\
\hline Task goal setting & Class tasks \\
\hline $\begin{array}{l}\text { Teachers to guide the main (students: "I want to } \\
\text { learn") }\end{array}$ & $\begin{array}{l}\text { teachers to explain the main (students: "I want to } \\
\text { learn") }\end{array}$ \\
\hline Focus on technical quality and target tasks & Focus on results and results \\
\hline Timely feedback, correct to standard & Summary \\
\hline
\end{tabular}




\section{Experimental results and analysis}

The technical and standard results of experimental group students have significant difference when compared with the control group, the experimental group have been greatly improved after the experiment in all aspects of the dig, both showing significant differences. After 8 weeks of study each link digging technology of the control group has improved, But only the mobile area and the shape of the hand, the hitting position have significant difference. This shows that the increasing effect of control group is not obvious, showed no significant difference, the experimental group has a better teaching effect. When we did the experiment, the original level of students, the teaching contents, the teaching process, time, location equipment, teachers and so on are under the condition of the same basic, so we think that the difference between the experimental result of the two groups is mainly due to the application of reasonable teaching objectives. The reasonable application in experimental teaching has obtained certain teaching effect. We believe that in the mat ball technology teaching, to set different teaching target in each lesson has a positive promoting effect on helping students to learn and master the ball technology, especially the ball with different height and far degrees, to realize and master the coordination of body force and to hand balls from different ways reasonably and flexibly. This can make students speed up to form the right action "dynamic stereotype", to improve the teaching effect, arouse the interest and motivation of students to master volleyball.

\section{Conclusion}

The experimental study of applying "goal setting teaching" in volleyball teaching in middle school students showed that both the technical action and standard scores of the experimental group students were better than the control group students. It is visible that goal setting theory applied in volleyball teaching is feasible and effective. The five skill evaluation scores before and after the experiment of the goal setting teaching experimental group have significant difference. But only individual projects of the control group without using "goal setting teaching" have significant difference before and after the experiment, the progress effect is not obvious. So the "goal setting teaching" can better promote the development of students' physical ability. The effect of the" goal setting teaching" experiment shows that the "goal setting teaching" helps students to determine the target, guides students to work hard for the target, can effectively improve the sports level of students, promote the development of students' sports ability. We suggest that the teaching goal should be based on the specific teaching and the situation of students. Teachers should use the "goal setting teaching" flexibly and adjust the teaching goal constantly. The teaching goals should be challenging, motivate students to pursue success.

\section{References}

[1] Ji Liu. Sports psychology. Higher education publishing house. 2006.46-73.

[2] Jiang Jingchuan, Liu Huashan. Research on the relationship between achievement goal orientation, learning strategy and academic achievement $[\mathrm{J}]$ psychological science, 2004, (01).

[3] Meng Hui, Ni Jie. A review of the relationship between goal orientation and performance and feedback seeking [J] psychological science, 2002, (04).

[4] Ames, etc. Classrooms:Goals, structures and, student motivation. [J]Journal of Educational psychology, 1992; 84:261-271.

[5] Elliot A J. J Approach and Achievement and Intrinsic Motivation:A Analysis. [J]Journal of Personality and Social Psychology, 1996176:628-644 Harackiewicz Mediational, Goals Avoidance M.

[6] Li Xiaodong, Zhang Bingsong. Relationship among achievement goals, social goals, self efficacy, academic achievement and academic help seeking [J] psychological science, 2001, (01).

[7] Zhang Yongmei, Fang Ping, Guo Chunyan. Experimental study on achievement goal classification and motivation model [J] psychological science, 1999, (05). 